\title{
Note sur les Mycetophilidae fossiles de l'ambre tertiaire.
}

Par Fernand Meunier de Bruxelles.

(Avec 3 Fig.)

Depuis les travaux de Loew, aucun paléoentomologiste ne s'est occupé de l'étude minutieuse des Mycetophilidae fossiles du succin. Les nouveaux genres crées par ce naturaliste ont été formés au moyen de caractères souvent très courts, et sans aucune indication iconographique.

Nous avons observé un curieux diptère appartenant à ce groupe, dont les nervures des ailes le rapprochent des genres Tetragoneura et Sciophila de la sous-famille des Sciophilinae.

Examinons comparativement les ailes des ces différentes mouches: Chez les Tetragoneura (Fig. 1), que nous signalons pour la première fois comme se rencontrant dans l'ambre tertiaire, la nervure basale des ailes atteint la première longitudinale, elle est parfois moins accusée; et, il existe toujours un trait transversal entre elle et la première nervure. La cellule quadrangulaire est formée par deux nervures transversales placées entre les deux premières longitudinales. La troisième est fourchue, la quatrième a une forme analogue; ou bien il y a seulement deux nervures qui se dirigent jusqu' à la base de l'aile.

Chez les Sciophila (Fig. 2) la nervure basilaire s'inseré au bord antérieur de l'aile, elle atteint souvent la cubitale; mais, elle est reliée par une nervure transversale à la sous-marginale. Cette dernière est réunie à la troisième longitudinale par une nervure transversale et produit une cellule trapéziforme. La nervure cubitale se termine par un trait transversal qui se réunit à la cellule précédemment citée.

Le fossile (Fig. 3), examiné sous un grossissement de 100 diamêtres a un millimêtre de longueur. Il. n'existe pas de nervure basilaire aux ailes. Toutefois, dans le genre Polylepta Winn., de la faune actuelle, elle est seulement peu accusée. La nervure sousmarginale arrive jusqu'au milieu de l'aile. La première longitudiale se réunit à la sous-marginale par un trait assez oblique et par une nervure transversale donnant naissance à une cellúle trapéziforme. Dans celle-ci se termine la nervure cubitale, qui est assez éloignée de l'extrémité de la sous-marginale. La fourche de la 4 . nervure longit. est plus longue que celle de la troisième. 


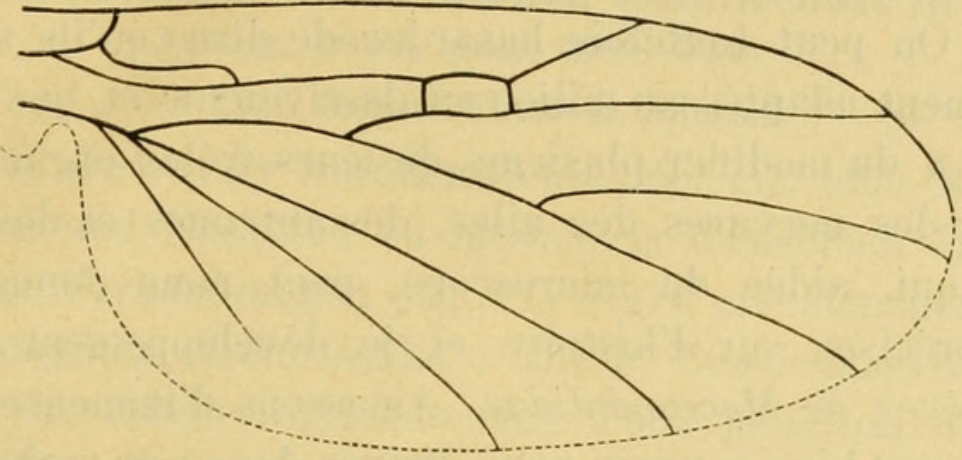

Fig. 1. Tetragoneura Winn. (selon V. der Wulp).

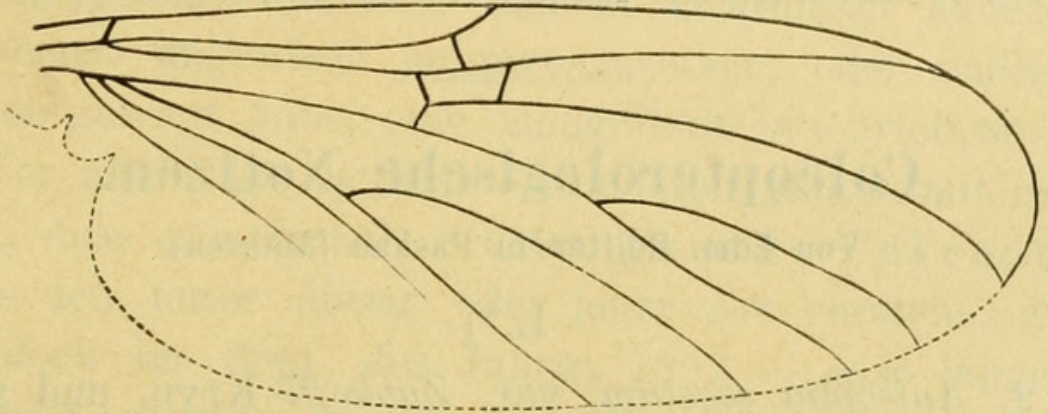

Fig. 2. Sciophila Meig. (selon V. der Wulp).

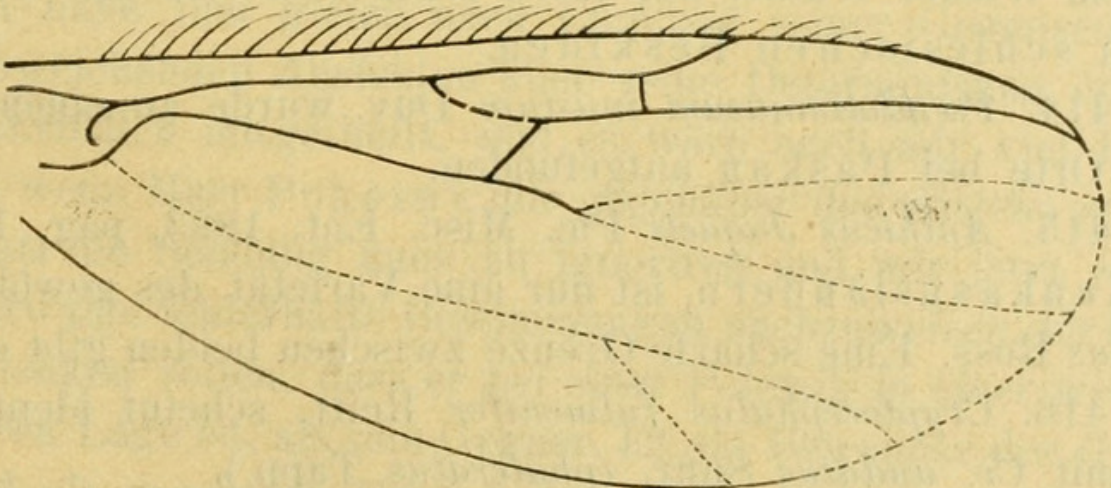

Fig. 3. Scudderiella mihi. 
Les documents, que nous possédons sur les genres de cette famille, sont encore trop insuffisants pour nous autoriser à indiquer conment ces êtres unt fait leur évolution pendant l'époque tertiaire. On peut toutefois hasarder de dire, qu'ils se sont merveilleusement adaptés au milieu où ils vivaient; et, que la sélection naturelle a du modifier plusieurs de leurs frêles organes. L'étude comparée des nervures des ailes, des antennes et des pattes est la seule qui, aidée du microscope, peut nous donner quelques notions précises sur l'histoire et le développement des minuscules espèces de Mycetophilidae. Amassons d'immenses matériaux d'études pour bien pouvoir nous diriger dans nos recherches, mais soyons très prudents dans nos conclusions et ne mentionnons actuellement que des faits.

Cependant nous nous permettons de créer pour cet intéressant fossile le genre Scudderiella, afin de rendre un humble hommage à l'éminent paléoentomologiste américain, si bien connu par ses admirables découvertes sur les articulés des périodes paléozoïques.

\title{
Coleopterologische Notizen.
}

\author{
Von Edm. Reitter in Paskaı (Mähren)
}

L.*)

412. Anisoplia segetum, var. Zubloffi Kryn. und v. rufipes Burm. (letztere nur aus Sibirien bekannt) wurden zahlreich von Herrn V. Plustschevsky-Plustschyk bei Astrachan gesammelt; ebenso Xanthochelus (Cleonus) Eversmanni Fst., Sphenoptera Karelini Fald.

413. Zilora Engeniae Ganglb., beschrieben nach Exemplaren aus dem Wiener Walde, fing Herr Rud. Schwab aus Friedland in den schlesischen Beskiden.

414. Pseudolimnaeum inustum Duv. wurde an einem schattigen Orte bei Paskau aufgefunden.

415. Anthicus Jaqueti Pic. Misc. Ent. 1893, pag. 127, aus den Kaukasusländern, ist nur eine Varietät des gewöhnlichen hispidus Ross. Eine scharfe Grenze zwischen beiden gibt es nicht.

416. Cryptocephalus fulmenifer Reitt. scheint identisch su sein mit Cr. undatus Suffr. (phaleratus Tapp.).

*) XIIIX. siehe Wien. Ent. Ztg. 1894, pag. 15. 


\section{$2 \mathrm{BHL}$ Biodiversity Heritage Library}

Meunier, Fernand Anatole. 1894. "Note sur les Mycetophilidae fossiles de I'ambre tertiaire." Wiener entomologische Zeitung 13, 62-64.

https://doi.org/10.5962/bhl.part.13216.

View This Item Online: https://www.biodiversitylibrary.org/item/44103

DOI: https://doi.org/10.5962/bhl.part.13216

Permalink: https://www.biodiversitylibrary.org/partpdf/13216

\section{Holding Institution}

Smithsonian Libraries

\section{Sponsored by}

Smithsonian

\section{Copyright \& Reuse}

Copyright Status: NOT_IN_COPYRIGHT

This document was created from content at the Biodiversity Heritage Library, the world's largest open access digital library for biodiversity literature and archives. Visit BHL at https://www.biodiversitylibrary.org. 